\title{
Evaluation of Yield Gain: A Case of Upland Rice Cultivation in Madagascar
}

\author{
Vololonirina Raharimanana and Raymond Rabeson \\ Rice Research Department, National Agricultural Research Institute (FOFIFA) \\ Madagascar
}

\begin{abstract}
Following the large dissemination of rainfed upland rice in Madagascar, this is to conduct yield gain among improved rice varieties through different fertilizer rates during the cropping season (2018/2019) in the Middle West at farmer's plot. It aims to analyze and to compare grain yields and their components for two popular varieties of rice such as Nerica 4 and B22. To assess potential yields of rice, it is assumed that nutrient and water stresses are the main biophysical factor limiting the yield of rainfed upland rice. By a random complete block device with three replications, the two rice varieties are respectively subjected to the following three fertilizer rate treatments such as T1: high quantity of crop nutrients, T2: low referring to Malagasy farmers' practices, T3: medium. Thus, for this year, the research released yield gain under a low-level of fertilization, with average yields of $1,55 \mathrm{~T} / \mathrm{Ha}$; against respectively $1,13 \mathrm{~T} / \mathrm{Ha}$ at medium and $1,58 \mathrm{~T} / \mathrm{Ha}$ at a high-level of fertilization conditions. This result may resolve not only socio-economic constraints with low input fertilizer but also water stress on rice cultivation.
\end{abstract}

Keywords: Rice, fertilizer, yield, upland

\section{Introduction}

Madagascar is part of a few countries in Sub-Saharan Africa that rice cultivation provides people' staple food (FAO, 2000). For the last two decades, this upland cropping system represents $17 \%$ of the rice fields (FAO, 2000). Due to food insecurity compared to demographic boom, water stress, nutrient depletion in the paddy soil, research has been undertaken "Yield Gain" trials during the rice crop season (2018/2019). Agricultural intensification can be achieved by improving agricultural practices through better crop management (FAO, 2000) and/or through improved and adapted varieties.

Yield gain can be obtained through coupling crop nutrient management and varietal improvement (AfricaRice, 2014). On the one hand, the rice farmers are interested in that yield gain is due to the optimal management conditions, by the nutrient improvement (Vandamne et al., 2015). Or, yield gain may be obtained in the context of Malagasy farmers' practices characterized by under- optimal conditions in nutrients (nutritional stress) or water supply (water stress). On the other hand, agronomic researchers need information on the potential yield of rice varieties under a given fertilizer application used by farmers. It is to implement decision-making tools effectively, such as the Nutrient Manager for Rice. Detailed knowledge of the phenological characteristics of the most important varieties is required by crop modelers. It is to make a more accurate prediction of 
potential yields in different agrosystems such as lowland or upland rice. That is to better identify in situ the dynamics of rice crop nutrient management widely adopted in the farmers' environment according to the soil conditions and the climatic variability (decreased soil fertility, water stress linked to the drought), and the socio-economic constraints (low purchasing power of farmers generating a low input of nutrients in their plot). So, this is the problem to be solved: What improved and profitable agricultural practices would we suggest for farmers in terms of grain yield, nutrient use efficiency, and economic returns at a strict rainfed upland ecology?

This trial was conducted in the Middle West of Madagascar:

- to assess, firstly, the yield gain and the potential yield of the rice varieties disseminated by FOFIFA / AfricaRice, widely adopted by Malagasy farmers;

- secondly, to determine the appropriate fertilization formula for upland rice in a given area.

As the predicted hypothesis, this is to verify:

H1: The good yield is provided by using improved varieties with a high fertilization rate for rainfed upland rice.

$\mathrm{H} 2$ : Each variety has its specific nutrient needs for a target yield, in a given area with water limitations.

\section{Method}

\section{Experimentation site}

It was implemented on -farm located in the Middle West of Madagascar. in Ankazomiriotra II, Rural municipality of Ankazomiriotra, Mandoto district, Vakinankaratra region. To be more accurate, it is at $19^{\circ} 40^{\prime} 6.6^{\prime \prime} \mathrm{S}$ and $46^{\circ} 32^{\prime} 60^{\prime \prime} \mathrm{E}$. The rainfall by decade is as follows:

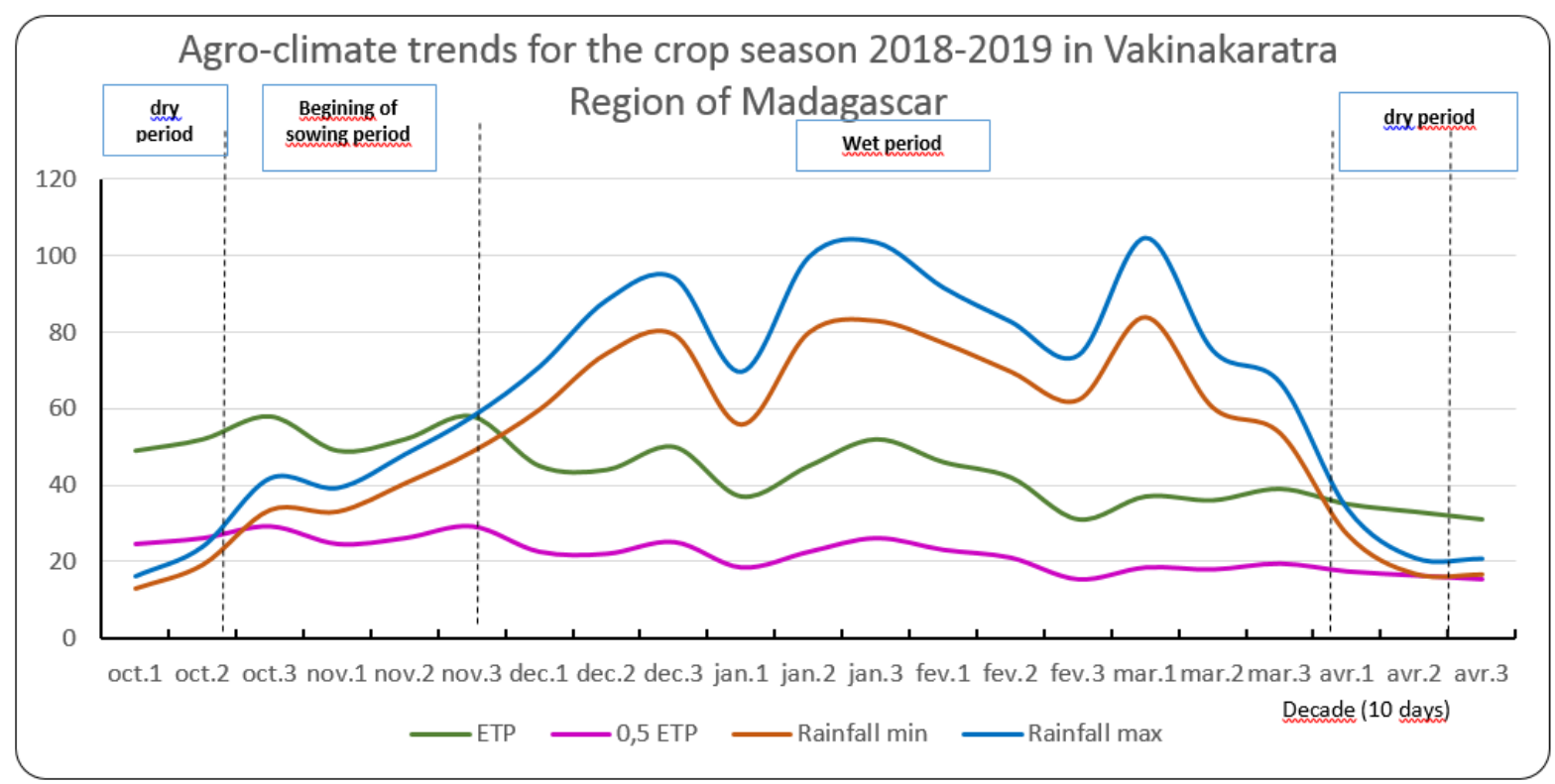

Figure 1: Rainfall trends (Source: DGM)

For upland rice cultivation, it may be implemented up to $60 \mathrm{~mm}$ of monthly rainfall, up to 0.5 ETP (evapotranspiration), for those that are under $900 \mathrm{~m}$ of elevation, knowing the ferralsoil characteristics in this region. The soil and organic fertilizer analysis are as follows: 
Table 1: Soil properties and basal organic fertilizer brought by farmers

\begin{tabular}{|l|r|r|r|r|r|r|r|}
\hline \multicolumn{1}{|c|}{ Parameters } & pH water & N\% & Pppm & C\% & MO\% & C/N & $\begin{array}{c}\mathrm{K} \\
\text { meq/100g }\end{array}$ \\
\hline $\begin{array}{l}\text { paddy soil with } \\
\text { monocutivation of rice }\end{array}$ & 5,42 & 0,056 & 0,1 & 0,534 & 0,92 & 9,535714 & 0,315 \\
\hline $\begin{array}{l}\text { paddy soil after crop } \\
\text { rotation legumes-rice }\end{array}$ & 5,61 & 0,056 & 3,4 & 0,637 & 1,09 & 11,4 & 0,15 \\
\hline Compost/farmyard manure & 8,06 & 0,81 & 0,16 & 12,1 & 20,81 & 14,19 & 0,55 \\
\hline
\end{tabular}

\begin{tabular}{|l|r|r|r|r|r|r|c|}
\hline \multicolumn{1}{|c|}{ Parameters } & \multicolumn{1}{|c|}{$\begin{array}{c}\mathrm{Na} \\
\mathrm{meq} / 100 \mathrm{~g}\end{array}$} & $\begin{array}{c}\mathrm{Ca} \\
\mathrm{meq} / 100 \mathrm{~g}\end{array}$ & $\begin{array}{c}\mathrm{Mg} \\
\mathrm{meq} / 100 \mathrm{~g}\end{array}$ & $\begin{array}{c}\text { Moisture } \\
(\%)\end{array}$ & $\begin{array}{c}\text { Clay } \\
\%\end{array}$ & $\begin{array}{c}\text { Limon } \\
\%\end{array}$ & $\begin{array}{c}\text { Sand } \\
\%\end{array}$ \\
\hline $\begin{array}{l}\text { paddy soil with } \\
\text { monocutivation of rice }\end{array}$ & 0,246 & 3,14 & 1,67 & & 14 & 19 & 67 \\
\hline $\begin{array}{l}\text { paddy soil after crop } \\
\text { rotation legumes-rice }\end{array}$ & 0,143 & 0,807 & 0,385 & & & & \\
\hline Compost/farmyard manure & 0,22 & 0,02 & 0,38 & 55,5 & & & \\
\hline
\end{tabular}

The soil is relatively poor in terms of nutrients, but the crop rotation increases its fertility and influences nutrient uptake.

\section{Design}

The design is characterized by RCBD (Complete Randomized Block Design) with three replications for each variety in each treatment, around $3 \mathrm{~m} * 3 \mathrm{~m}$ per plot.

The management of nutrients helps to evaluate potential yields. The previous crop for all treatments is legumes as it can be uniform, following crop rotation "legumes/rice/legumes/rice" during many successive seasons. The severity of water stress imposed in upland rice will depend on rainfall during the experimentation.

T1: 7,7 Tonnes of compost $/ \mathrm{ha}+1112 \mathrm{~kg}$ of urea $/$ ha (high fertilizer input, rate split in two times)

T2: 3,88 Tonnes of compost/ha $+278 \mathrm{~kg}$ of urea /ha (low fertilizer input)

T3: 7,7 Tonnes of compost $/ \mathrm{ha}+556 \mathrm{~kg}$ of urea $/$ ha (medium fertilizer input)

The layout is as follows:

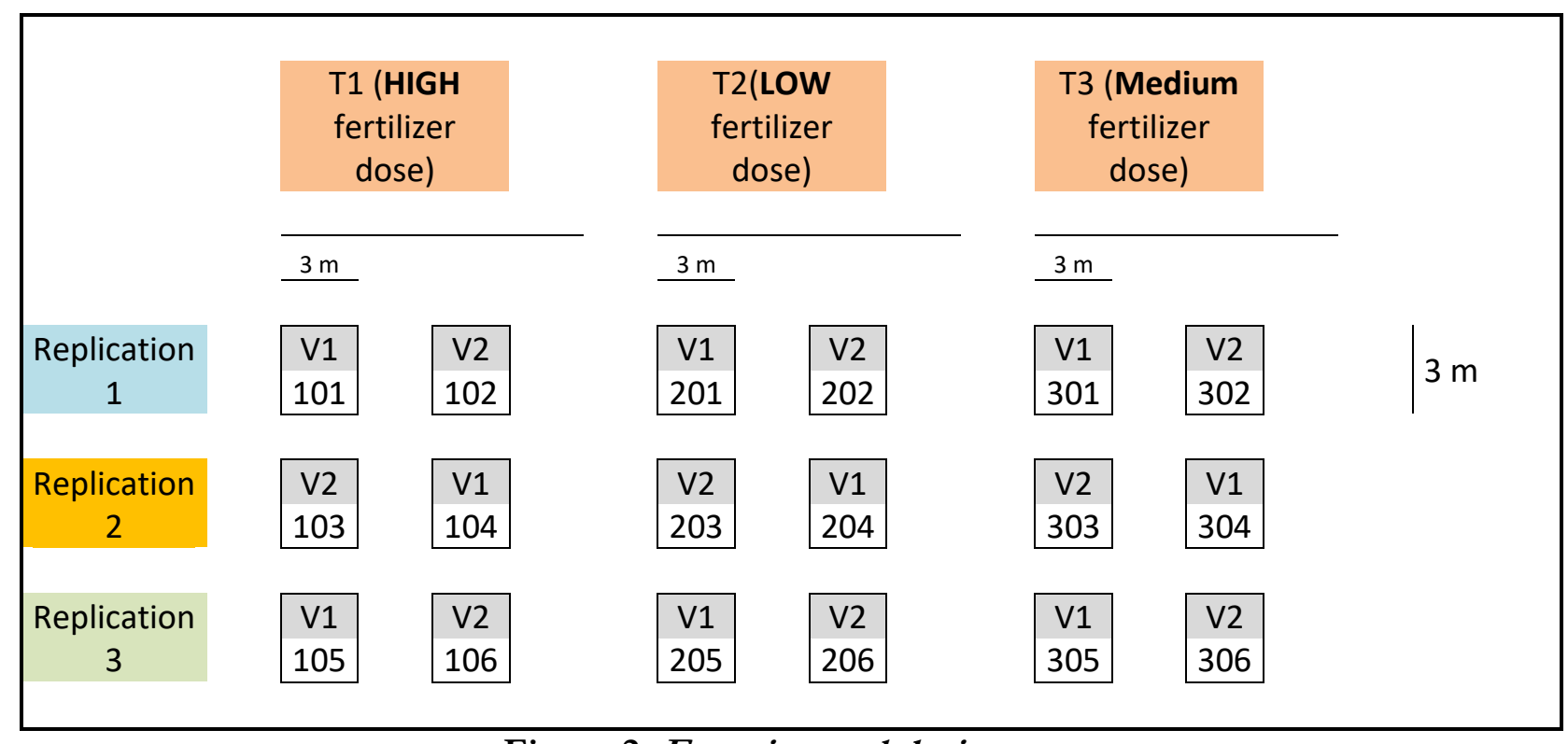

Figure 2: Experimental design 


\section{Materials}

Two (2) varieties were tested, representative of the varieties which were most widely adopted by Malagasy rice farmers for several years from $900 \mathrm{~m}$ to $1200 \mathrm{~m}$ of elevation. These varieties are selected mainly for their character of better yield and better plant growth with a cycle duration of 100 to 120 days, regarding a specific resistance to abiotic and biotic stress (Striga Asiatica, so on).They are recorded in Table 2:

Table 2: List of released varieties

\begin{tabular}{|l|c|}
\hline$N^{\circ}$ & Variety/cultivar \\
\hline V1 & Nerica 4 \\
\hline V2 & B22 \\
\hline
\end{tabular}

\section{Procedure}

The types of fertilizer used, the period of application, and the quantity of fertilizer for each treatment are given in Table 3:

Table 3: Treatments, fertilizer types, time and Rate of intake

\begin{tabular}{|c|c|c|c|}
\hline \multicolumn{4}{|l|}{ T1: HIGH fertilizer input } \\
\hline Nutrient: & Basal & \multicolumn{2}{|c|}{ Topdressing (broadcasting method) } \\
\hline Type of fertilizer used: & Compost & Urea & Urea \\
\hline Application period (JAS): & $\begin{array}{l}\text { At plowing } \\
\text { time }\end{array}$ & $14 \mathrm{JAS}$ & 30JAS \\
\hline Rate (kg of NUTRIENT ha-1): & & $256 \mathrm{~N}$ & $256 \mathrm{~N}$ \\
\hline Rate (kg of fertilizer.ha-1): & 7700 & 556 & 556 \\
\hline \multicolumn{4}{|l|}{ T2: LOW fertilizer input } \\
\hline Nutrient: & Basal & \multicolumn{2}{|c|}{ Topdressing (broadcasting method) } \\
\hline Type of fertilizer used: & Compost & Urea & Urea \\
\hline Application period (JAS): & $\begin{array}{l}\text { At plowing } \\
\text { time }\end{array}$ & $14 \mathrm{JAS}$ & 30JAS \\
\hline Rate (kg of NUTRIENT ha-1): & & $128 \mathrm{~N}$ & $0 \mathrm{~N}$ \\
\hline Rate (kg of fertilizer.ha-1): & 3880 & 278 & 0 \\
\hline \multicolumn{4}{|l|}{ T3: MEDIUM fertilizer input } \\
\hline Nutrient: & Basal & \multicolumn{2}{|c|}{ Topdressing (broadcasting method) } \\
\hline Type of fertilizer used: & Compost & Urea & Urea \\
\hline Application period (JAS): & $\begin{array}{l}\text { At plowing } \\
\text { time }\end{array}$ & $14 \mathrm{JAS}$ & 30JAS \\
\hline Rate (kg of NUTRIENT ha-1): & & $256 \mathrm{~N}$ & $0 \mathrm{~N}$ \\
\hline Rate (kg of fertilizer.ha-1): & 7700 & 556 & 0 \\
\hline
\end{tabular}

JAS = days after sowing;

* A sample of the manure used is analyzed for determining N, P, and K grades. For each treatment, a complete randomized block device with 3 replications.

It has been sowing by $20 \mathrm{~cm} * 20 \mathrm{~cm}$ as an interval. During the rice-growing season, we did the best on managing and controlling other factors such as insects and weeds, we focus our study on fertilizer effects, water stress, and varieties responses. They are among the key factors for rice yield gain. 


\section{Results}

The results of the ANOVA are shown in Table 4. Figure three illustrates yield variation according to treatment and cultivars. It appears that, statistically, from a treatment point of view, there is no significant difference between T1, T2, and T3 as well as between V1 and V2 (by XL STAT 2016 software); they are at the same category. However, only the interaction T1V1 differs significantly to others, such as:

\begin{tabular}{lrrrrr}
\hline Category & LS means & $\begin{array}{c}\text { Standard } \\
\text { error }\end{array}$ & $\begin{array}{c}\text { Lower bound } \\
(95 \%)\end{array}$ & $\begin{array}{c}\text { Upper bound } \\
(95 \%)\end{array}$ & Groups \\
\hline T1*V2 & 1,1916 & 0,1909 & 0,7870 & 1,5962 & $\mathrm{~A}$ \\
T2*V1 & 1,1916 & 0,1909 & 0,7870 & 1,5962 & $\mathrm{~A}$ \\
$\mathrm{~T} 2 * \mathrm{~V} 2$ & 1,1916 & 0,1909 & 0,7870 & 1,5962 & $\mathrm{~A}$ \\
$\mathrm{~T} 3 * \mathrm{~V} 1$ & 1,1916 & 0,1909 & 0,7870 & 1,5962 & $\mathrm{~A}$ \\
$\mathrm{~T} 3 * \mathrm{~V} 2$ & 1,1916 & 0,1909 & 0,7870 & 1,5962 & $\mathrm{~A}$ \\
$\mathrm{~T} 1 * \mathrm{~V} 1$ & 2,6014 & 0,4268 & 1,6967 & 3,5062 & $\mathrm{~B}$ \\
\hline
\end{tabular}
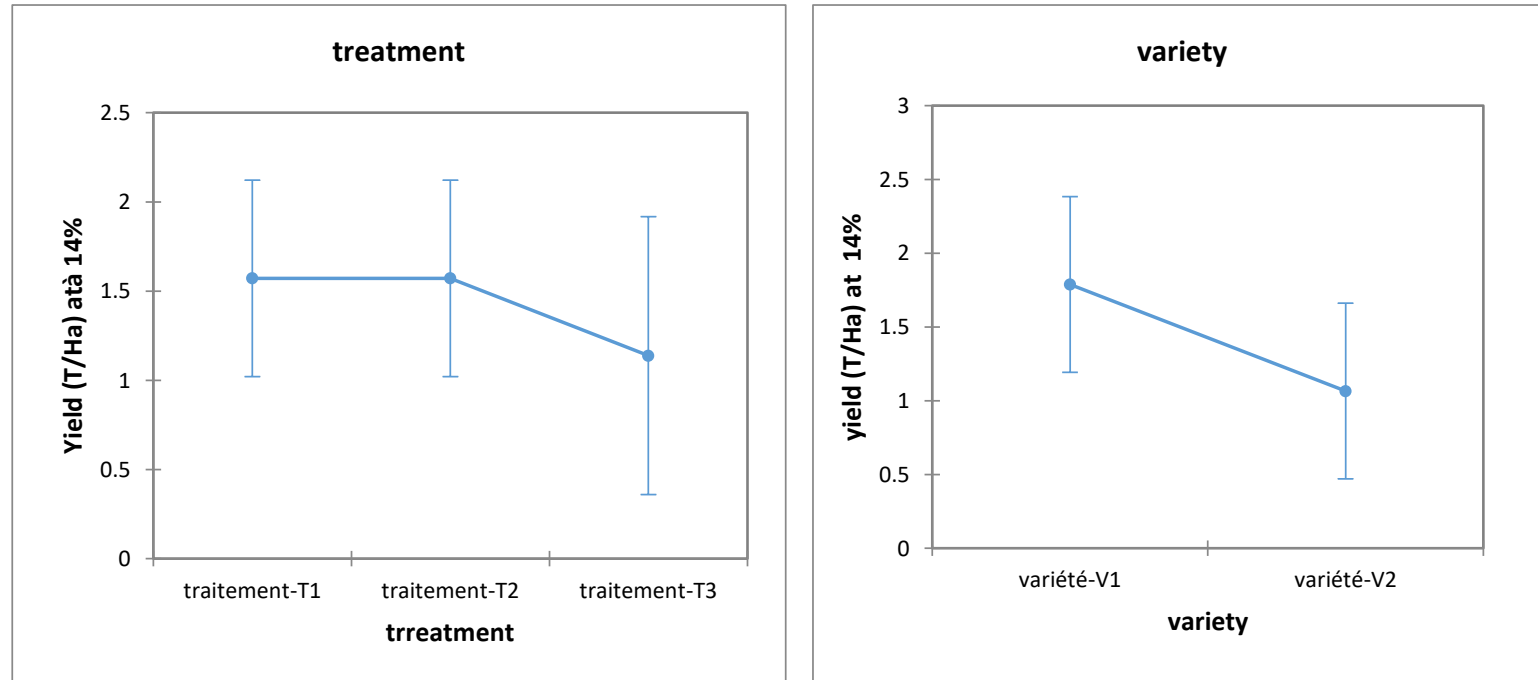

Figure 3: Overview of calculated yield variation according to treatment and types of varieties

T1 and $\mathrm{T} 2$ show almost similar yield (on average of 1,58T/Ha against respectively 1,55T/Ha), statistically no significant, even though the fertilizer rate is completely different. Generally, V1 is highly productive than V2 as their cycle duration are respectively 120 days against 100 days; it means particularly much more vegetative development with much more fertile tillers and plant height as below.

Then, the analysis of variance according to these factors will be:

Table 4: Results of ANOVA

\begin{tabular}{|l|l|l|l|l|l|l|l|l|l|}
\hline TREATMENT & $\begin{array}{l}N^{\circ} \\
\text { VARIETY }\end{array}$ & $\begin{array}{c}\text { Number of } \\
\text { the fertile } \\
\text { tillers }\end{array}$ & \multicolumn{2}{|c|}{$\begin{array}{r}\text { Plant } \\
\text { Height }(\mathrm{cm})\end{array}$} & \multicolumn{2}{|c|}{$\begin{array}{r}\text { *Calculated yield in T/ha } \\
\text { at } 14 \% \text { of humidity }\end{array}$} & \multicolumn{2}{|c|}{$\begin{array}{l}\text { Real yield in } \\
\text { T/ha }\end{array}$} \\
\hline T1 & V1 & 16,11 & a & 88,56 & a & 2,60144169 & b & 2,70 & b \\
\hline T1 & V2 & 13,22 & a & 82,89 & a & 0,57220397 & a & 1,94 & a \\
\hline T2 & V1 & 12,67 & a & 71,33 & a & 1,31314002 & a & 1,89 & a \\
\hline
\end{tabular}




\begin{tabular}{|l|l|l|l|l|l|l|l|l|l|} 
T2 & V2 & 14,11 & a & 69,22 & a & 1,80 & a & 2,00 & a \\
\hline T3 & V1 & 15,22 & a & 76,00 & a & 1,44841178 & a & 2,30 & a \\
\hline T3 & V2 & 13,89 & a & 85,89 & a & 0,82731794 & a & 2,26 & a \\
\hline
\end{tabular}

${ }^{*}$ Calculated yield $=$ Number of the fertile tillers (or panicles) per area*Number of grains per panicle*fertile and filled grains*grain weight

These results show us that: with a high rate of fertilizers, the yield of V1 and V2 are respectively 2,70T/Ha and 1,96T/Ha. Nevertheless, with low fertilizer input, V1 and V2 have 1,89T/Ha and $2 \mathrm{~T} / \mathrm{Ha}$ respectively. Finally, with a medium fertilizer application, V1 has 2,30T/Ha and V2 for 2,26T/Ha. Then, V2 responds relatively well to low input fertilizer as V1 to the high nutrient application.

Table 5: Yield components

\begin{tabular}{|l|l|l|r|r|r|}
\hline Treatment & Variety & Replication & $\begin{array}{l}\text { Number of } \\
\text { spikelets } \\
\text { per panicle }\end{array}$ & $\begin{array}{l}\text { Grain } \\
\text { fertility } \\
\text { percentage }\end{array}$ & $\begin{array}{l}\text { 1000 grains } \\
\text { weight } \\
\text { (grams) }\end{array}$ \\
\hline T1 & V1 & R1 & 80,00 & 77,50 & 7,313 \\
\hline T1 & V1 & R2 & 92,00 & 85,14 & 11,718 \\
\hline T1 & V1 & R3 & 87,33 & 70,61 & 8,914 \\
\hline T1 & V2 & R1 & 72,00 & 69,44 & 7,603 \\
\hline T1 & V2 & R2 & 73,00 & 53,42 & 3,337 \\
\hline T1 & V2 & R3 & 70,33 & 13,74 & 3,771 \\
\hline T2 & V1 & R1 & 83,33 & 78,00 & 6,483 \\
\hline T2 & V1 & R2 & 76,33 & 84,72 & 7,056 \\
\hline T2 & V1 & R3 & 80,67 & 83,06 & 5,608 \\
\hline T2 & V2 & R1 & 75,67 & 72,25 & 9,030 \\
\hline T2 & V2 & R2 & 88,00 & 78,79 & 8,944 \\
\hline T2 & V2 & R3 & 75,00 & 70,67 & 7,159 \\
\hline T3 & V1 & R1 & 78,33 & 89,79 & 8,336 \\
\hline T3 & V1 & R2 & 78,33 & 67,23 & 3,967 \\
\hline T3 & V1 & R3 & 67,00 & 70,65 & 7,740 \\
\hline T3 & V2 & R1 & 76,33 & 72,05 & 4,898 \\
\hline T3 & V2 & R2 & 65,00 & 67,18 & 4,362 \\
\hline T3 & V2 & R3 & 77,33 & 73,28 & 4,399 \\
\hline
\end{tabular}

These components determine paddy yield as each panicle bears many spikelets, but they are partially filled, that's why their weight is too low compared to the target weight (FOFIFA, 2010).

\section{Discussion}

Regarding improved varieties, released by National Research, both Nerica 4 and B22 are resilient to water stress (drought) for middle elevation in Madagascar, according to varietal distribution (SNDR, 2016). Their responses to fertilization might be settled by many filed experiments, compared to local and traditional varieties. They are slightly higher yields not only under abiotic and biotic stress but also under optimal conditions (Raharimanana, 2018). As usual, yield response to fertilizer rate in the experiments with varying light intensity is illustrating by increased sensitivity 
to an added fertilizer (Bockel et al., 2001). However, in this study, it is not the case. It seems very important to underline that up to a convenient fertilizer rate, varieties do not respond significantly in terms of yield. It suggests that although under dry ferralitic soil, as nutrients may be a limiting factor, yield reduction may have resulted in an overdose of fertilizer application. The average yield does not exceed 1,58T/Ha whatever the fertilization rate, except the top of 2,04T/Ha for T1V1, by combining high fertilization $(562 \mathrm{~N})$ with adapted variety (Nerica 4 ) which is impossible for most of the Malagasy farmers. Simultaneously, other agricultural constraints such as drought should be one of the factors. It implicates a significant loss in terms of investment, considering the cost and accessibility of these mineral fertilizers by farmers. Yet, for degraded soil of the Middle West of Madagascar, with a high attack of Striga Asiatica, upland rice yield is around 0 to $1 \mathrm{~T} / \mathrm{Ha}$ without fertilizer application (Rakotondramanana, 2013). Hence, the appropriate fertilizer rate is one of the requirements of the improved varieties, which has not been well -respected at the farmer level (Bockel et al., 2001). Moreover, advanced agricultural technologies can increase yield in eight times (Rakotoson, 2013). That's why this study provides information for implementing accurate agriculture in Madagascar to help farmers in their decision making in terms of fertilization. Consequently, in this study area, these varieties B22 and Nerica 4 are highly yielded at the appropriate fertilizer input not only its quantity (rate) but also its quality (other elements such as $\mathrm{P}, \mathrm{K}$, and so on).

Apart from that, as far as nutrient mobilization is concerned, soil moisture is very required for its better management (Raharimanana, 2018). Rainfall is one of the critical factors for upland rice as it may suffer from drought at the booting stage. Other research confirmed that the water deficit reduced rice plant growth duration, its height, and its tillering, its root biomass, and especially its grain fertility (Hassane, 2017). Therefore, concerning this affirmation, Huguet (1996) said that raising leaf nitrogen from $\mathrm{N}$ to $4 \mathrm{~N}$ increases grains sterility at $30 \%$. It is a symptom of Nitrogen overtop in rice and then causes maturity delay. Besides, high fertilizer rate is making plants to produce more tillers per hill, but coupling with water deficit, while grains per panicle per tiller are decreasing its filling ability. It is shown by a low 1000 grains weight (Lalanirina, 2014). Nevertheless, during this crop season, according to the rainfall data, it does not seem strictly severe. In this study, the more we increase the fertilizer rate (for T3 comparatively to T2), the more we have a yield slightly decreased $1.55 \mathrm{~T} / \mathrm{Ha}$ to $1,13 \mathrm{~T} / \mathrm{ha}$. Yield losses go around 0.99 to $34.92 \%$ if the nutrient is inadequate as -2.32 to $53.99 \%$ if the water is not well controlled (Raharimanana, 2018). It suggests that yield potential for these varieties is not well expressed in these conditions. It can reach till 4 to $5 \mathrm{~T} / \mathrm{Ha}$ for the other upland rice cropping system (such as SCV or the use of plant cover without plowing), as an average of 2,3Tof grains per hectare (Rakotondramanana, 2013).

Furthermore, in this cropping system point of view, in this study, the previous crop "legumes" is providing nutrients for the rice, especially the massive returns of organic carbon to soil (Bechini et al., 2009) and then nitrogen to plant nutrition. There are more additional Nitrogen inputs by a significant quantity of farmyard manure or compost per plot. Despite the fact that Nitrogen is one of the limiting factors in Malagasy paddy soil, the high number of tillers and the plant height comparatively to grains weight shows nutritional unbalance. In other words, rice plant seems to lose time for tiller and leaf fabrication instead of accumulating grain glucose reserve (Gros, 1962). Hence, soil content may be dominated by nitrogen than the other major elements such as phosphorus. According to Matsuo et al., (2016), it is better to assess soil chemistry and nutrient status of soil in an attempt to improve the productivity of rainfed uplands. The result is as flows at the end of the vegetation period. 
Table 6: Soil analysis at the end of tillering stage

\begin{tabular}{|l|r|l|l|r|r|r|r|r|r|r|}
\hline $\begin{array}{l}\text { Soil simple } \\
\text { under } \\
\text { treatment }\end{array}$ & $\begin{array}{l}\mathrm{pH} \\
\text { water }\end{array}$ & $\mathrm{N} \%$ & $\mathrm{Pppm}$ & $\mathrm{C} \%$ & $\mathrm{MO} \%$ & $\mathrm{C} / \mathrm{N}$ & $\begin{array}{l}\mathrm{K} \\
\mathrm{meq} / \\
100 \mathrm{~g}\end{array}$ & $\begin{array}{l}\mathrm{Na} \\
\mathrm{meq} / \\
100 \mathrm{~g}\end{array}$ & $\begin{array}{l}\mathrm{Ca} \\
\mathrm{meq} / \\
100 \mathrm{~g}\end{array}$ & $\begin{array}{l}\mathrm{Mg} \\
\mathrm{meq} / \\
100 \mathrm{~g}\end{array}$ \\
\hline check & 5,61 & 0,056 & 3,4 & 0,637 & 1,09 & 11,4 & 0,15 & 0,143 & 0,807 & 0,385 \\
\hline T1 & 5,51 & 0,091 & 4,1 & 0,996 & 1,71 & 10,9 & 0,135 & 0,149 & 1,87 & 0,875 \\
\hline T2 & 5,7 & 0,115 & 4,9 & 1,2 & 2,06 & 10,4 & 0,154 & 0,133 & 2,15 & 0,912 \\
\hline T3 & 5,42 & 0,112 & 4,5 & 1,18 & 2,03 & 10,5 & 0,115 & 0,196 & 1,68 & 0,743 \\
\hline
\end{tabular}

This result shows us the nutrient perdition during the growth cycle, which is not uptake by rice. It is a waste of urea application by nitrogen volatility and hydric erosion if it is not immediately absorbed by the plant. Indeed, nitrogen absorption is different for variety with short cycle duration (B22) than those with medium/long cycle (Nerica 4) as its pick is a little bit shifted [Tanaka et al., (1966), recited by De Datta (1981)]. Moreover, the fact of splitting nitrogen fertilizer two times during the vegetative period is more beneficial (Rakotoarisoa, 2011) as it reduces nitrogen perdition.

To be profitable, this may help agronomists to review the appropriate dose of nitrogen for a target yield, considering specifically plant needs for their growth and reproduction. For many years, FOFIFA recommended, for upland rice in the Middle West of Madagascar, to adopt crop rotation and to apply up to 5 Tonnes of organic fertilizer per Hectare, 60 to $90 \mathrm{~N}, 30 \mathrm{P}_{2} \mathrm{O}_{5}$, and 20 to $30 \mathrm{~K}_{2} \mathrm{O}$ for a target grain yield of $4 \mathrm{~T} / \mathrm{h}$. Consequently, the appropriate rate of fertilization goes under $\mathrm{T} 2$ (low fertilizer rate in this trial). On the other side, Zhao et al., (2016) suggests that increasing soil organic matter enhances inherent soil productivity while offsetting the fertilization effect under a rice cropping system. Therefore, it is better to focus on fertilization investment by increasing significantly organic matter application as its content is showed in table1. By its decomposition and mineralization, it improves soil properties, then plant nutrition. It may be helpful and profitable for farmers regarding the cost of chemical fertilizers comparatively to farmyard manure, and particularly the low input fertilizer ability of rice farmers (SNDR, 2016). Research should contribute by improving nutrient use efficiency and economic returns, with existing farmers' fertilizer practices (Singh et al., 2014). Increasing the productivity and resilience of smallholder farming systems is a huge challenge. It will require significant and sustained technical, financial, and political support and action at both the national and local levels (Harvey, Rakotobe, Rao, Radhika, Razafimahatratra, Rabarijohn, Rajaofara \& MacKinnon, 2014). These technical capacities for several years allow Malagasy farmers to adapt to some risks (Penot, Dabat, Rakotoarimanana, Grandjean, 2014). Therefore, reducing fertilizer rate and better making value the low chemical fertilizer input is among mitigation strategies to water stress, especially for upland rice, considering the cost of fertilizer unit (Galabi et al., 2011). It joined the ambition of FAO in 2016 that cereals farmers adopt the components and the essential practices of « Produce more with less » model. Crop rotation based successively by legumes such as bean and rice is more productive; yield increases by $25.5 \%$ through the incorporation of residual farmyard manure, crop residues, and biofertilizers (Davari et al., 2012).

\section{Conclusion}

Through this study, the first hypothesis is partially confirmed. Using a convenient rate of fertilizer input (chemical and organic) combined with an adapted variety, is highly productive at a given area to avoid nutrient perdition. It is harmful to the environment and economics knowing farmers' constraints. It may suggest that it is better to increase organic matter quantity instead of chemical fertilizer. The first one improves soil properties and provides plant nutrition by progressive decomposition and mineralization at convenient climatic conditions. This result joins what FOFIFA has been doing for many years. Farmers should bring compost up to $5 \mathrm{~T} / \mathrm{Ha}$, and nitrogen 
fertilizers at the right rate.It is variable according to soil organic matter content and its ratio carbon by nitrogen $\mathrm{C} / \mathrm{N}$. it requires the next research to determine this dose accurately. In this sense, each variety has his own needs as far as nutrient management is concerned, in a given area. It depends on its cycle duration. Finally, this study helps each category of farmers not to apply under or overdose of chemical fertilizers considering its agronomic, environmental, and economic impacts. The average grain yield does not exceed $1,58 \mathrm{~T} / \mathrm{Ha}$ even though combined with a great potential variety. According to FAO, the downward trend in productivity must be reversed. It focuses not only on the balanced nutrient that will reduce the problems associated with overexploitation of the land; but also on good control of water. It may suggest the other upland rice cropping system which conserves soil moisture at the right rate and enriches soil organic carbon.

\section{References}

AfricaRice. (2014). Rice yield growth analysis for 24 African countries over 1960-2012. Retrieved from https://www.researchgate.net/publication/267760928_Rice_yield_growth_analysis_for_24_Afri can_countries_over_1960-2012

Bechini, L., \& Castoldi, N. (2009). On-farm monitoring of economic and environmental performances of cropping systems: Results of a 2-year study at the field scale in northern Italy. Ecological Indicators, 9(3), 10961113. https://doi.org/10.1016/j.ecolind.2008.12.008

Bockel, L., \& Dabat, M. H. (2001). Améliorer la productivité du travail dans la riziculture pour lutter contre la pauvreté à Madagascar [Improving labor productivity in rice cultivation to fight poverty in Madagascar]. Séminaire international «La pauvreté à Madagascar: état des lieux, facteurs explicatifs et politiques de réduction " Antananarivo, 5-7 février 2001, CIRAD.

Davari, M., Sharma, S. N., \& Mirzakhani, M., (2012). Residual influence of organic materials, crop residues, and biofertilizers on the performance of succeeding mung bean in an organic rice-based cropping system. International Journal of Recycling of Organic W aste in Agriculture volume, (1)14, 1-9.

FAO. (2009). Le défi technologique. Comment nourrir le monde en 2050 [The technological challenge. How to feed the world in 2050]. Forum d'experts de haut niveau. Rome 12-13 Octobre 2009.

FAO. (2016). Produire plus avec moins en pratique [Producing more with less in practice]. Guide for sustainable cereal production.

FOFIFA. (2010). Catalogue national des espèces et variétés cultivées à Madagascar [National catalog of species and varieties cultivated in Madagascar.], Première edition.

Gala, B. T. J., Camara, M., Yao-kouame A., \& Keli, Z. J. (2011). The profitability of mineral fertilizers on rainfed upland rice cultivation: a case of Gagnoa zone in the middle west of Côte d'Ivoire. Journal of Applied Bioscience, 46, 3153-3162.

Gros, A. (1962). Engrais, guide pratique de la fertilisation [Fertilizers, a practical guide to fertilization]. Troisième édition entièrement révisée. Paris.

Harvey, C. A., Rakotobe, Z. L., Rao, N. S., Radhika, D., Razafimahatratra, H., Rabarijohn, R. H., Rajaofara, H., \& MacKinnon, J. L. (2014). The extreme vulnerability of smallholder farmers to agricultural risks and climate change in Madagascar. The Royal Society publishing. Philos Trans R Soc Lond B Biol Sci., 369(1639).

Hassane, A. (2017). Effets du stress hydrique sur la culture de deux variétés de riz pluvial [Effects of water stress on the cultivation of two varieties of upland rice] (Oryza Sativa L.) FOFIFA 3729 et FOFIFA 3737 (Master Dissertation). University of Antananarivo, Faculty of Sciences.

Huguet, F. (1966). Physiologie et technologie du riz en relation avec la nutrition azotée [Physiology and technology of rice in relation to nitrogen nutrition]. In Bulletin d'information de la riqiculture de France, 103, 1-13.

Lalanirina, M. S. (2014). Modélisation de la production de biomasse du blé en réponse au stress hydrique : cas de la parcelle d'Aurade [Modeling of wheat biomass production in response to water stress : the case of the Aurade plot] (Master Dissertation). ESS A University of Antananarivo.

Matsuo, K., Ae, N., Vorachit, S., Thadavon, S., Areas, N., \& Pdr, L. (2016). Present Soil Chemical Status and Constraints for Rice-Based Cropping Systems in Vientiane Plain and Neighboring Areas, Lao PDR. Journal of Plant Production Science, 18(3), 314-322. https://doi.org/10.1626/pps.18.314 
MPAE. (2016). Stratégie Nationale de Développement Rizicole (SNDR) 2016-2020. Ministère Auprès de la Présidence en charge de l'Agriculture et de l'Elevage de Madagascar.

Penot E., Dabat, M. H., Rakotoarimanana, A., \& Grandjean, P. (2014). L'évolution des pratiques agricoles au lac Alaotra à Madagascar. Une approche par les temporalités. [The evolution of agricultural practices in Lake Alaotra in Madagascar. An approach through temporalities]. Biotechnol. Agron. Soc. Environ., 18(3), 329-338.

Raharimanana, V., \& Rabeson, R. (2018). Evaluation of Genetic Yield Gain: a case of lowland rice growing in Madagascar. International Journal of Humanities and Social Sciences, 10(5), 27-37.

Rakotoarisoa, N. M. (2011). Suivi des effets du supergranule d'urée (SGU) sur la riziculture irriguée en comparaison avec l'urée perlée apportée par fractionnement: cas de la commune rurale de Mahitsy [Monitoring the effects of urea supergranule (SGU) on irrigated rice cultivation in comparison with pearl urea provided by fractionation: case of the rural commune of Mahitsy] (Dissertation). Ecole Supérieure des Sciences Agronomiques, Université d'Antananarivo Madagascar.

Rakotondramanana. (2013). Riziculture et SCV à Madagascar [Rice cultivation and SCV in Madagascar]. Retrieved from www.gsdm-mg.org

Rakotoson, P. (2013). Aperçu actuel sur les filières riz-maïs-oignon-grains [Current overview of the ricecorn-onion-grain sectors]. Séminaire "L L sécurité alimentaire dans l'Indianocéanie, Investir dans la production agricole » 25-27 Mars 2013, Mahajanga Madagascar. Minsitère de l'Agriculture.

Singh, V. K., Dwivedi, B. S., Tiwari, K. N., Majumdar, K., Rani, M., Singh, S. K., \& Timsina, J. (2014). Field Crops Research Optimizing nutrient management strategies for rice - wheat system in the IndoGangetic Plains of India and adjacent region for higher productivity, nutrient use efficiency and profits. Field Crops Research, 164, 30-44. https://doi.org/10.1016/j.fcr.2014.05.007

Tanaka, A., Mulleriyawa, R. P., \& Yasu, T. (1966). Possibility of hydrogen sulfide induced iron toxicity of the rice plant. Soil science and plant nutrition, 14(1), 1-6.

Vandamme, E., Rose, T., Saito, K., Jeong, K., \& Wissuwa, M. (2015). Integration of P acquisition efficiency, $\mathrm{P}$ utilization efficiency and low grain $\mathrm{P}$ concentrations into P-efficient rice genotypes for specific target environments. Nutrient Cycling in Agroecosystems, 104, 413-427.

Zhao, Y., He, X., Huang, X., Zhang, Y., \& Shi, X., (2016). Increasing Soil Organic Matter Enhances Inherent Soil Productivity while Offsetting Fertilization Effect under a Rice Cropping System. Sustainability 2016, 8(9), 879. https://doi.org/10.3390/su8090879 